\title{
Water supply intensity during drip irrigation of vegetable crops
}

\author{
S.A. Kurbanov, M.M. Dzhambulatov, V.V. Borodychev, and D.S. Magomedova* \\ Dagestan State Agrarian University, Makhachkala, Russia \\ The branch of the All-Russian Research Institute of Hydraulic Engineering and Land Reclamation of \\ A.N. Kostyakov, Volgograd, Russia
}

\begin{abstract}
The paper presents the materials of field research on the study of the regularities of the development of moisture outlines on light soils during drip irrigation of vegetable crops. The correlation is found between the depth of the moistened layer and the area of the moistening outlines on the pre-irrigation threshold of the moisture content of the active soil layer, irrigation standards and the flow rate of drippers, which gives an opportunity to decline the unproductive water consumption for filtration. It is found that in light loamy and sandy loam light chestnut soils, for guaranteed rule of the moisture regime, on onion crops, it is essential to maintain the pre-irrigation threshold of $80 \% \mathrm{HB}$ with the irrigation rate of $200 \mathrm{~m} 3$ / ha with the flow rate of drip water outlets of $2.81 / \mathrm{h}$, and the depth of irrigation of $120 \mathrm{~m} 3 / \mathrm{ha}$ with the flow rate of discharge outlets of $1.7 \mathrm{l} / \mathrm{h}$, correspondingly. In irrigation of tomatoes grown on light-loamy light-chestnut soils, it is appropriate to apply the irrigation rate of $180 \mathrm{~m} 3 / \mathrm{ha}$, which provides the level of pre-irrigation humidity in the layer of $0.6 \mathrm{~m}$ not lower than $80 \% \mathrm{HB}$, the formation of the required characteristics of the moisture contour (depth of $0.62 \mathrm{~m}$ and diameter of $0.37 \mathrm{~m}$ ), as well as an enhance in the efficiency of irrigation water use by $11.1 \%$. The results can be applied in the design of drip irrigation systems for vegetable crops.
\end{abstract}

\section{Introduction}

Upgrading the land reclamation complex in the arid regions of the south of the country is a difficult task and is closely associated with the issues of rational land use and improving the environmental situation [1]. This is particularly important for the irrigated zone of the Republic of Dagestan, the largest region of irrigated agriculture in Russia, where in recent decades there has been a decline in the condition of irrigated land due to secondary salinization, ascent of the ground water level and other issues related to the fact that the majority of the republic's water supply systems were built in the last century [2] and have an efficiency of 0.52 . In these conditions, the transition from the traditional surface irrigation method to resource-saving drip irrigation in the republic will considerably reduce water losses for runoff and infiltration, and maintain the agrophysical parameters of the irrigated soil fertility [3].

\footnotetext{
${ }^{*}$ Corresponding author: mds-agro@mail.ru
} 
Drip irrigation is based on the water supply through a network of pipelines via droppers, facilitating the local moistening of the soil. The shape and characteristics of local moisture depends on the water-physical features of the soil, the threshold of pre-irrigation humidity, the flow rate of water outlets, the duration of irrigation, the intensity of physical evaporation from the soil surface, and other factors $[4,5]$. The above factors have a considerable impact on the characteristics of the humidification circuit, the concept of irrigation water distribution in it, as well as the nature of the root system development, on the degree of development of which the efficiency of moisture-loving vegetable crops depends. The studies on the rules of the formation of moisture contours have been carried out mainly on soils of medium and heavy granulometric composition [6-11], and there is very little data on the development of moisture contours for light soils [12]. This is particularly important in the view of the agricultural development of unproductive light-loamy and sandy lands, the area of which in Dagestan alone is more than 400 thousand hectares, which defined the direction of our investigations.

\section{Materials and methods}

The aim of the study was to determine the regularities of the development of moisture contours on light soils in the cultivation of onions and tomatoes with the use of drip irrigation to identify a rational irrigation rate for the use of water resources. According to the aim of the research, two tasks had to be solved:

- to study the regularities of moisture distribution and to identify the humidity control zone of light loamy and sandy loam soil during drip irrigation of vegetable crops;

- to set the best pre-irrigation moisture threshold for the active layer of onions and tomatoes, as well as elements of drip irrigation technology for the efficient use of irrigation water.

Onion crops have particular requirements, identified by the biology of the crop, for the formation of a soil moisture contour. During the sowing of onions with a ribbon eight-line method, the drip lines are spread out in pairs with a distance between the paired drip pipes of $0.5 \mathrm{~m}$. This determines the necessity of forming a humidification contour with a minimum horizontal size of $0.5 \mathrm{~m}$, which provides for the closing of the humidification zones and the formation of a single moisture strip. This condition is adequate, as it enables us to maintain a favorable water treatment regime in the area where the plants are spaced. The best depth of soil moisture in the cultivation of onions is $0.5 \mathrm{~m}$, which is proved by the results of numerous studies performed in the distribution zone of light chestnut soils [13, 14, 15]. For the study of the characteristics of the humidification circuits (depth and diameter), the rate of water flow in the droppers was varied from 0.3 to $4.2 \mathrm{l} / \mathrm{h}$ and the level of preirrigation humidity was changed from 70 to $90 \%$ HB. In order to control the soil moisture in the humidification circuits, a TR-46908 strain gauge was used (Italy).

In the test area of tomatoes, the drip irrigation network included irrigation pipes (lines) through $1.4 \mathrm{~m}$ with semi-compensated drip water outlets built through $0.3 \mathrm{~m}$ with a flow rate of $1.6 \mathrm{l} / \mathrm{h}$. Planting of tomatoes of the Sunrise hybrid was performed by the band method when creating rows of plants at a distance of $0.2 \mathrm{~m}$ on both sides of the drip tube.

The volume of water $(60 \mathrm{~m} 3 / \mathrm{ha})$ supplied in one hour and the relevant change in the parameters of the humidification circuit are used as a step in differentiating the levels of the experiment. Irrigation standards were defined according to the generally accepted method, based on the level of pre-irrigation humidity of the active soil layer of 70,80 and $90 \% \mathrm{HB}$, taking into account the ratio of the volume of the soil to be moistened. Therefore, the scheme of the field experience was as follows:

- type 1 - irrigation rate of $60 \mathrm{~m}^{3} /$ ha to provide a humidification circuit $0,40 \times 0,25 \mathrm{~m}$; - type 2 - irrigation rate of $120 \mathrm{~m}^{3} /$ ha, to provide a humidification circuit $0,50 \times 0,30 \mathrm{~m}$; 
- type 3 - irrigation rate of $180 \mathrm{~m}^{3} /$ ha, to provide a humidification circuit $0,60 \times 0,35 \mathrm{~m}$.

\section{Results and discussion}

The wetting depth of the soil (h) and the diameter of the wetting contour (d) are the main indicators that characterize the volume of the wetted soil when using drip irrigation. The values of the irrigation standard and the production of drippers, the level of pre-irrigation soil moisture, the moisture capacity and water permeability of the soil, depending on its granulometric composition, should have the greatest impact on the characteristics of the local humidification zone. Our investigations enabled us to determine the patterns of changes in the parameters of the soil moisture contour from the value of the irrigation standard and the level of pre-irrigation soil moisture. The wetting depth and diameter in the zone of the maximum water supply (the state of the lowest water capacity) naturally grow with the increase in the irrigation rate, as evidenced by the multiple regression equation with the coefficient of determination $\mathrm{R}^{2}=0,96$ :

$$
y=-41.883+353.2499 X_{1}+35.4068 X_{2}
$$

where $\mathrm{X}_{1}$ - depth of the humidification circuit, $\mathrm{m}$;

$\mathrm{X}_{2}$ - diameter of the humidification circuit, $\mathrm{m}$.

The parameters of the moisture contours are also influenced by the level of preirrigation soil moisture. For example, at a pre-flood humidity of $70 \% \mathrm{MWC}$, the ratio of the parameters of the humidification circuit (h:d) is 0.72 , at $80 \% \mathrm{MWC}-0.96$, and at $90 \%$ MWC - 1.81. So, with an increase in the initial humidity, the rate of vertical absorption in light soils exceeds the rate of horizontal movement of moisture. At $70 \% \mathrm{MWC}$, this shows insufficient water supply of the active layer of onions, and at $90 \%$ - overspending of irrigation water. Statistical processing of the experimental data received using the software product STATISTICA 13.3 has provided the dependences between the characteristics of the moisture contour and the levels of pre-irrigation soil moisture. The dependencies are described by regression equations:

$$
\begin{gathered}
h=\frac{a+b \times w+c \times w^{2}+d \times q}{1+e \times w+f \times q} \\
d=a+\frac{b}{w}+c \times \ln \times q+\frac{d}{w^{2}}+e \times \ln \times q^{2}+f \times \frac{\ln \times q}{w}
\end{gathered}
$$

where $\mathrm{h}, \mathrm{d}$ - wetting circuit values parameters (wetting depth and diameter), $\mathrm{m}$; $\mathrm{w}-$ the level of pre-irrigation soil moisture, $\% \mathrm{MWC}$;

$\mathrm{q}$ - drip water outlet flow rate, $\mathrm{l} / \mathrm{h}$;

a, b, c, d, e, f - dependency values specified by statistical data processing (tab. 1).

\begin{tabular}{|c|c|c|c|c|c|c|c|}
\hline \multirow{2}{*}{ Response function } & \multicolumn{6}{|c|}{ Dependency settings } & \multirow{2}{*}{$\begin{array}{l}\text { Coefficient of } \\
\text { determination, } \\
\mathrm{R}^{2}\end{array}$} \\
\hline & $a$ & $b$ & $c$ & $d$ & $e$ & $f$ & \\
\hline Wetting depth (h) & -0.03 & 0.0018 & $-1.47 \cdot 10^{-5}$ & 0.03 & -0.01 & -0.0014 & 0.95 \\
\hline $\begin{array}{c}\text { Humidification } \\
\text { diameter, } \mathrm{d}\end{array}$ & 0.4 & 9.33 & -0.035 & -806 & -0.02 & 13.1 & 0.97 \\
\hline
\end{tabular}

Table1. Regression coefficients of the equation of the dependence of the values of the soil moisture contour under drip irrigation on the level of pre-irrigation soil moisture and irrigation standard

Graphs of dependencies are presented in Figures 1 and 2. 


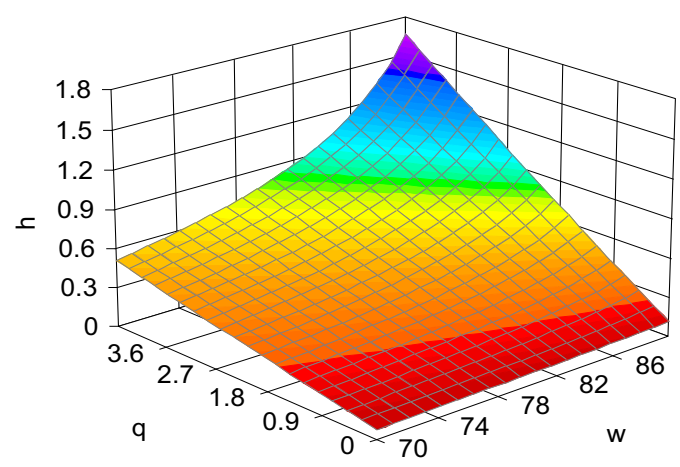

Fig. 1. Dependence of the soil wetting depth $(h, m)$ on the level of pre-irrigation humidity (w, \% MWC) and the flow rate of drip water outlets (q, $1 / \mathrm{h})$.

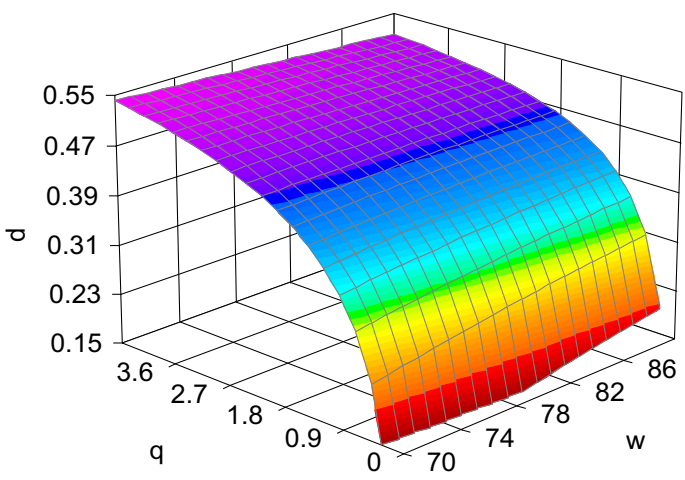

Fig. 2. Dependence of the diameter of the moisture contour (in, $\mathrm{m}$ ) on the level of pre-irrigation soil moisture (w, \% MWC) and the flow rate of drip water outlets $(\mathrm{q}, \mathrm{l} / \mathrm{h})$.

The values of the moisture contours are also affected by the granulometric composition of the soil. If the irrigation standard defines the overall growth in the size of the humidification contour, then at the same pre-rain threshold $(80 \% \mathrm{MWC})$, the shape of the humidification contour depending on the type of soil and the flow rate of the droppers, which can be characterized in the nearest approximation by the ratio of the depth and diameter of the humidification zone. On light-loamy light-chestnut soils, the best values of the moisture contour in onion crops are obtained by the application of irrigation pipelines with a dropper flow rate of $2.8 \mathrm{l} / \mathrm{h}$. In sandy loam soils, with the same flow rate of drippers, the soil moisture contour is converted, stretched in a vertical profile, and decreased in horizontal size. Meanwhile, the moisture depth rises to $0.73 \mathrm{~m}$, which significantly outstrips the capacity of the biologically based horizon and results in overspending of irrigation water. This sets the challenge of selecting the performance of droppers for soils of different granulometric composition. It was established that for sandy soils, the most optimal ratio of the values of the moisture contour is formed at the flow rate of $1.7 \mathrm{l} / \mathrm{h}$.

On light-loamy soils, the rise in the flow rate of droppers to $3.61 / \mathrm{h}$ did not result in the development of the necessary values of the moisture contour, since at the achieved moisture depth of $0.5 \mathrm{~m}$, the diameter of the moisture contour was $0.4 \mathrm{~m}$, which decreased the zone of root nutrition of onion plants. On sandy soils, when the desired moisture depth was achieved, the diameter of the moisture contour was only $0.34 \mathrm{~m}$. A further rise in the flow rate of drip water releases to $4.21 / \mathrm{h}$ was followed by a further transformation of the wetting circuit and led to an even greater excess of the wetting depth over the diameter of the wetting circuit at a ratio of 1.1...1.4. 
The dependence of the depth and diameter of the moisture contour on the flow rate of drippers for light loamy and sandy loam soils is shown by the linear regression equations with the coefficient of determination $\mathrm{R}^{2}=0,96$ and 0,87 respectively:

$$
\mathbf{y}=0.200 x+0.077 \text { and } y=0.040 x+0.366
$$

The growth in the dynamics of vertical water absorption with an increase in the flow rate of droppers should be considered when selecting the scheme of sowing onions and the distance between the droppers on the irrigation pipes (lines). From our point of view, on light-loamy and sandy light-chestnut soils, it is required to downsize the distance between drippers on irrigation pipelines from 0.3 to $0.15 \ldots 0.20 \mathrm{~m}$. This suggestion will be tested when setting up a field experiment.

Therefore, considering the dependence of the moisture contours on the levels of the preirrigation moisture content of the soil, the size of the irrigation standards, the flow rate of drippers and the granulometric composition of the soil, for the rational utilization of water with optimal water supply for onion crops, it is essential to maintain a pre-irrigation moisture threshold of at least $80 \% \mathrm{MWC}$ in a layer of $0.5 \mathrm{~m}$ with a flow rate of $2.8 \mathrm{l} / \mathrm{h}$ for light loamy and $1.7 \mathrm{l} / \mathrm{h}$ for sandy light chestnut soils.

The influence of irrigation standards on the differentiation of the formed humidification zones in the local drip irrigation circuit was found on tomato plantings grown on light loamy soils. The variation in the irrigation rate from 60 to $180 \mathrm{~m} 3 /$ ha during drip irrigation results in the differentiation of the moisture contour into three zones: excessive $(100 \ldots 110 \%$ MWC), optimal (95...100\% MWC) and insufficient (70...95\% MWC) moisture. When the pre-irrigation threshold of soil moisture rises in the humidification circuit from 14.2 to $8.1 \%$, the zone of excessive soil moisture reduces and the zone of optimal moisture declines from 41.7 to $21.2 \%$, as well as the zone of transition of the soil state with a biologically optimal level of moisture after watering to the condition of the soil with insufficient moisture before watering from 18.9 to $8.5 \%$ (fig. 3 ).

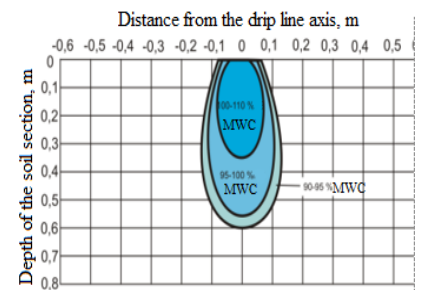

$70 \% \mathrm{MWC}$

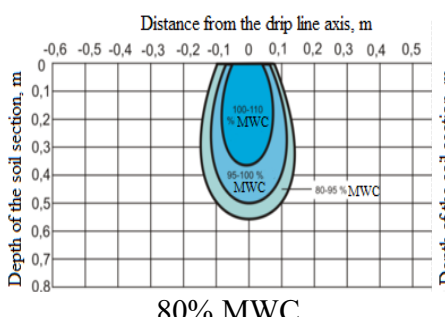

$80 \% \mathrm{MWC}$

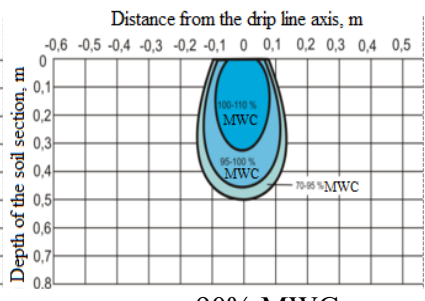

$90 \% \mathrm{MWC}$

Fig. 3. Moisture contour at soil moisture thresholds.

Research has shown that no more than $71.2 \%$ of all irrigation water is used in the zone of the humidification circuit, where the moisture content remains ideal for tomatoes during the inter-irrigation period. The lowest share of irrigation water in the humidification circuit$57.4 \%$. It is available at the pre-irrigation humidity level of $70 \% \mathrm{MWC}$, and with a rise in the pre-irrigation humidity level to $90 \% \mathrm{MWC}$, the share of irrigation water in the circuit rises to $71.2 \%$.

The analysis of the data made helps to determine the most rational value of the irrigation standard on light loamy soils for the tomato crop $-180 \mathrm{~m}^{3} /$ ha, at which the required parameters of the moisture contour of $0.62 \times 0.37 \mathrm{~m}$ are formed and the organization of a continuous field of soil moisture along the drip tube (line) is ensured. At the irrigation rate of $180 \mathrm{~m}^{3} / \mathrm{ha}$, the most productive use of irrigation water is ensured, as indicated by the lowest value of the water consumption coefficient- $61.2 \mathrm{~m}^{3} / \mathrm{t}$, and at the irrigation rate of $120 \mathrm{~m}^{3} /$ ha- $68.8 \mathrm{~m}^{3} / \mathrm{t}$. 
The transition from corrugational to drip irrigation presupposed not only a decrease in the irrigation rate, but also an improvement in the efficiency of the use of moisture, including irrigation water. The main index of the efficiency of the use of moisture for the development of agricultural crops is the coefficient of water consumption [16-18].

The determination of total water consumption and tomato yield data received at different levels of pre-irrigation soil moisture help us to propose a non-linear regression formula for determining the tomato water consumption coefficient depending on the factors that characterize the parameters and the water-air regime of the soil in the humidification circuit using mathematical statistics:

$$
K_{B}=X_{1}+X_{2}+X_{3}+X_{4}+X_{1}^{2}+X_{2}^{2}+X_{4}^{2}+X_{2} \cdot X_{1}+X_{2} \cdot X_{4}
$$

where $K_{B}$ - tomato water consumption coefficient, $\mathrm{m}^{3} / \mathrm{t}$;

$\mathrm{X}_{1}$ - depth of the humidification circuit, $\mathrm{m}$;

$\mathrm{X}_{2}$ - diameter of the humidification circuit, $\mathrm{m}$;

$\mathrm{X}_{3}$ - soil porosity within the boundaries of the moisture profile, $\%$;

$\mathrm{X}_{4}$ - the share of the "transition" zone in the humidification circuit, \%.

The analysis of the calculated water consumption coefficients received and using the above formula confirmed the good convergence of the results obtained, since the dissimilarity did not exceed $9.3 \%$.

\section{Conclusion}

The most significant factors determining the quantitative and qualitative side of water intake and distribution in drip irrigation are the irrigation rate, the granulometric composition and flow rate of drippers, and to a lesser extent the level of pre-irrigation soil moisture. Research has shown that on light soils, with an increase in the irrigation rate, the rate of vertical absorption outstrips the rate of horizontal movement of moisture by 2.3 times. The best pre-watering humidity threshold for watering onions is $80 \% \mathrm{MWC}$, at which the ratio of the values of the moisture contour $(\mathrm{h}: \mathrm{d})$ is close to the biologically optimal and is 0.964 , at $70 \%$ MWC- 0.725 , and at $90 \%$ MWC -1.81 .

In order to make efficient use of water with optimal water supply for onion crops, it is required to maintain a pre-irrigation moisture threshold of at least $80 \% \mathrm{MWC}$ in a layer of $0.5 \mathrm{~m}$ with a flow rate of $2.8 \mathrm{l} / \mathrm{h}$ for light loamy and $1.7 \mathrm{l} / \mathrm{h}$ for sandy light chestnut soils.

The best moisture contour for tomatoes under drip irrigation is $0.62 \times 0.37 \mathrm{~m}$ when using the irrigation standard of $180 \mathrm{~m} 3 / \mathrm{ha}$, which raises the efficiency of the use of moisture and irrigation water by $11.1 \%$, on light-loamy light - chestnut soils.

\section{References}

1. A. M. Menshikh, Pot \& Veg, 9, 2-7 (2017)

2. Z.M. Kurbanov, Lan. Recl \& Wat. Man, 5, 11-15 (2016)

3. S.A. Kurbanov, Proc. of the Nizhn. Agr. Com, 1, 130-136 (2019)

4. S. Von Westarp S, Agr. Wat. Man, 2(64), 143-160 (2004)

5. A.V. Ould Mohamed El-Hafedh, Ic J, 49, 15-28 (2000)

6. S.M. Vasilyev, Lan. Rec \& Wat. Man, 1, 16-19 (2019)

7. D.E. Kucher, Lan. Recl \& Wat. Man, 6, 5-9 (2015)

8. A.S. Ovchinnikov, Proc. of the Nizhn. Agr. Com, 4 (16), 43-47 (2009)

9. R.V. Prokopets, Ag. Sc. J, 4, 62-65 (2015) 
10. A.V. Shuravilin, Lan. Recl \& Wat. Man, 2, 35-37 (2014)

11. N.N. Dubenok, Veg of Rus, 2, 74-77 (2020)

12. S.A. Kurbanov, Sc L, 11, 1648-1657 (2019)

13. E. Babicheva, Lead Agr, 9, 57-59 (2013)

14. V.V. Borodychev, Lan. Recl \& Wat. Man, 2, 31-33 (2011)

15. R.V. Kalinichenko, Lan. Recl \& Wat. Man, 2, 18-21 (2019)

16. V.V. Borodychev, Proc. of the Nizhn. Agr. Com, 1(18), 167-175 (2018)

17. V.A. Kulygin, Sc j of Rus Res In of Cr Gr, 2(18), 1-15 (2015)

18. N.V. Tyutyuma, Proc of Gor St Ag Un, 54(3), 32-38 (2017) 